\title{
Association of Class Attendance and Academic Performance of MBBS Students in Anatomy
}

Dr. Viren B. Kariya ${ }^{1}$, Dr. Lalit C. Ratanpara ${ }^{2 *}$

${ }^{1}$ Associate Professor, Department of Anatomy, PDU Govt. Medical College, Rajkot, Gujarat, India

${ }^{2}$ Tutor, Department of Anatomy, PDU Govt. Medical College, Rajkot, Gujarat, India

\author{
DOI: $10.36348 /$ SIJAP.2019.v02i09.002 \\ | Received: 04.09.2019 | Accepted: 11.09.2019 | Published: 20.09.2019 \\ *Corresponding author: Dr. Lalit C. Ratanpara
}

\section{Abstract}

Objectives: Student's absenteeism is a continuous problem in medical education despite mandatory attendance policies introduced by universities. Medical education demands high attendance for good understanding and grasps over the subject. The objective of present study is to assess the strength of association between class attendance percentage and marks obtained in internal examination of Anatomy subject. Methods: Retrospective observational studies of first MBBS students who have passed Anatomy examination in 2017 and 2018 (150 students in each batch) were included and their attendance as well as marks of internal examination of both theory and practical were retrieved and correlated. Statistical analysis was carried out to find the strength of association between attendance and internal marks. Results: The findings in present study suggest a positive improvement in mean marks obtained in both theory and practical exam as percentage of attendance increases. Conclusion: The findings of present study support the evidence that there is a significant correlation between attendance percentages their academic performance in theory and practical.

Key words: Class attendance, Academic performance, Percentage, Association, Anatomy, MBBS students.

Copyright @ 2019: This is an open-access article distributed under the terms of the Creative Commons Attribution license which permits unrestricted use, distribution, and reproduction in any medium for non-commercial use (NonCommercial, or CC-BY-NC) provided the original author and source are credited.

\section{INTRODUCTION}

To study in a medical college has a high demand to attend the classes of both theory and practical, as the curriculum is very vast and students are being exposed to many concepts for the first time. During classes of theory and practical learning occurs very significantly [5]. A lot of emphasis has been laid down by the universities and regulatory bodies on attendance policies. Most of the universities have kept $75 \%$ as the cut off for eligibility to appear in the university exams [6]. Student attendance is an important part of professional development and it is measured as an evidence of professionalism [5].

Students absenteeism is an alarming situation particularly in first MBBS as the duration is very short and maximum concepts are required to be built in this limited time span[6]. Some of the reason behind absenteeism which are cited in literature are illness, tiredness, lack of interest/motivation, finding the class boring, prioritizing other academic work and some personal reasons [8].

One more emerging reason for student absenteeism might be availability of online material, access to PowerPoint presentations, the students are now able to access a wealth of information and to study at their own convenience. Consequently, this raises the issue of whether missing class (physical absence from the classroom) still impacts on student learning as it used to do before the recent technological advances. There have been a numerous studies across the disciplines of health, medical sciences, psychology, economics and the physical science that have indicated in earlier years a positive correlation between class attendance and performance [8].

Anatomy is an essential subject in medical education that contributes effective knowledge of human body. The classroom lectures as well as practical sessions of dissection and histology are the primary teaching methods in anatomy. The lecture based learning enhances the cognitive, affective and psychomotor skills despite being didactic in nature and having poor feedback. Cadaveric dissection being the most effective tool for improving students' knowledge, goes by had with theory classes for better concept building and understanding[5].

The effect of attendance on students grades has not been evaluated effectively in Medical Education in 
Indian set ups and the causes for the same have not been explored. [6].

Hence, present study was carried out to find the strength of association between percentage of class attendance and marks obtained in internal examination of both theory and practical.

\section{MATERIALS AND METHODS}

Study design: A retrospective observational study of first MBBS undergraduate students who have passed Anatomy examination in 2017 and 2018 (150 students in each batch) was conducted in Department of Anatomy of PDU Govt. Medical College, Rajkot, and Gujarat, India.

The first MBBS students who have passed Anatomy examination were included in the study. Theory and Practical marks of anatomy of $1^{\text {st }}$ terminal and preliminary examinations conducted for the batch of 2016-17 and 2017-18 first MBBS was retrieved. Similarly, data of the attendance percentage of both theory and practical of same students were also retrieved.

Following three groups were made based on the percentage of attendance.

Group: I: less than $80 \%$ of attendance

Group: II: between $81 \%$ and $90 \%$ of attendance

Group: III: more than $90 \%$ of attendance

\section{DATA ANALYSIS}

Data was entered and analyzed in Microsoft Excel. additionally, Karl Pearsons correlation coefficient was used to test the strength of association between percentage of attendance and internal marks.

\section{RESULTS}

- Karl pearsons correlation coefficient between attendance and marks

Table -1 and Table -2

There was a positive correlation between attendance percentage and marks of both theory and practical which was significant as indicated by karl pearsons formula.

\section{- Comparison of attendance percentage with mean theory marks}

Table -3

Above findings suggest there is positive improvements in mean marks obtained in theory exam as the percentage of attendance increases from group I to group III.

\section{- Comparison of attendance percentage with mean practical marks} Table -4

Above findings suggest there is positive improvements in mean marks obtained in practical exam as the percentage of attendance increases from group I to group III.

Table-1: Comparison of attendance percentage with marks in theory

\begin{tabular}{|c|c|c|}
\hline YEAR & EXAM : THEORY & CORREL COEFFICIENT : ATTENDANCE VS MARKS \\
\hline \multirow{2}{*}{$2016-17$} & $1^{\text {st }}$ TERMINAL EXAM & 0.329 \\
\cline { 2 - 3 } & PRELIM EXAM & 0.433 \\
\hline \multirow{2}{*}{$2017-18$} & $1^{\text {st }}$ TERMINAL EXAM & 0.388 \\
\cline { 2 - 3 } & PRELIM EXAM & 0.417 \\
\hline
\end{tabular}

Table-2: Comparison of attendance percentage with marks in practical

\begin{tabular}{|c|c|c|}
\hline YEAR & EXAM : THEORY & CORREL COEFFICIENT : ATTENDANCE VS MARKS \\
\hline \multirow{2}{*}{$2016-17$} & $1^{\text {st }}$ TERMINAL EXAM & 0.420 \\
\cline { 2 - 3 } & PRELIM EXAM & 0.480 \\
\hline \multirow{2}{*}{$2017-18$} & $1^{\text {st }}$ TERMINAL EXAM & 0.414 \\
\cline { 2 - 3 } & PRELIM EXAM & 0.489 \\
\hline
\end{tabular}

Table-3

\begin{tabular}{|c|c|c|c|c|c|}
\hline YEAR & EXAM : THEORY & GROUP & ATTENDANCE & MEAN MARKS & SD \\
\hline \multirow{7}{*}{$2016-17$} & \multirow{3}{*}{$1^{\text {st }}$ TERMINAL EXAM } & I & $<80$ & 28.41 & 12.76 \\
\hline & & II & $81-90$ & 34 & 10.1 \\
\hline & & III & $>90$ & 40.63 & 10.42 \\
\hline & & & & & \\
\hline & \multirow{3}{*}{ PRELIM EXAM } & $\mathrm{I}$ & $<80$ & 58.03 & 12.91 \\
\hline & & II & $81-90$ & 54.7 & 6.42 \\
\hline & & III & $>90$ & 58.36 & 9.02 \\
\hline \multirow{6}{*}{$2017-18$} & \multirow{3}{*}{$1^{\text {st }}$ TERMINAL EXAM } & $\mathrm{I}$ & $<80$ & 26.25 & 8.55 \\
\hline & & II & $81-90$ & 32.54 & 11.01 \\
\hline & & III & $>90$ & 37.92 & 8.06 \\
\hline & \multirow{3}{*}{ PRELIM EXAM } & 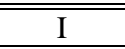 & $<80$ & 45.16 & 7.44 \\
\hline & & II & $81-90$ & 54.58 & 7.33 \\
\hline & & III & $>90$ & 58.48 & 8.91 \\
\hline
\end{tabular}


Table- 4

\begin{tabular}{|c|c|c|c|c|c|}
\hline YEAR & EXAM : THEORY & GROUP & ATTENDANCE & MEAN MARKS & SD \\
\hline \multirow[t]{6}{*}{$2016-17$} & \multirow[t]{3}{*}{$1^{\text {st }}$ TERMINAL EXAM } & I & $<80$ & 44.72 & 16.8 \\
\hline & & II & $81-90$ & 65.61 & 10.69 \\
\hline & & III & $>90$ & 66.94 & 4.3 \\
\hline & \multirow{3}{*}{ PRELIM EXAM } & I & $<80$ & 55.67 & 13.39 \\
\hline & & II & $81-90$ & 63.88 & 6.27 \\
\hline & & III & $>90$ & 66.71 & 5.22 \\
\hline \multirow[t]{6}{*}{$2017-18$} & \multirow[t]{3}{*}{$1^{\text {st }}$ TERMINAL EXAM } & $\mathrm{I}$ & $<80$ & 56.03 & 11.31 \\
\hline & & II & $81-90$ & 60.55 & 11.08 \\
\hline & & III & $>90$ & 64.55 & 6.53 \\
\hline & \multirow[t]{3}{*}{ PRELIM EXAM } & I & $<80$ & 58.38 & 6.03 \\
\hline & & II & $81-90$ & 64.19 & 6.43 \\
\hline & & III & $>90$ & 67.67 & 6.23 \\
\hline
\end{tabular}

\section{DISCUSSION}

Despite mandatory attendance (at least 75\%) policies student's absenteeism is a continuous problem in medical education. To acquire skills for better performance in future and to understand the subject in a proper way high attendance in both theory and practical course is essential in medical profession.

In present study it is found that there is a strong correlation between percentage of attendance and student's academic performance in both theory and practical. Additionally it is also observed that mean marks of both theory and practical are also found to be improved along with group I to III (from $<80$ to $>90 \%$ of attendance).

The results of present study are comparable to similar study conducted by Varul et al. [7] which reported a significant positive correlation between attendance and academic performance in both theory and practical examination. Similarly, present study results are being supported by Chilwant and Hundekari et al. [1] which concluded positive correlation attendance and test score in theory examination. However, they have not found correlation between attendance and test score in practical examination.

Present study findings are also in line with other studies like one carried by Hamdi et al. [3] and another by Daud and javaid et al. [2] showing significant effect of absenteeism on level of achievement in medical education.

\section{STUDY LIMITATIONS}

In present study to know the academic performance only attendance as one variable was taken into consideration. However, other confounding factors like class size, study habits, illness, tiredness, lack of interest, boring classes, teacher absenteeism communication skill, cultural, social factors and personal reasons were also required to fully understand impacting attendance and/or academic performance.

\section{CONCLUSION}

This study found a significant association between attendance percentage and academic performance in both theory and practical.

Academic outcome is correlated with cognition and motivation of students. Both of this is influenced by attendance of students. The cognition helps in process, integration and recalling of information where as motivation having about behavioral changes to enable them to be self-directed learners [4].

The findings of present study will helpful in shaping institutional policies regarding attendance monitoring. Additionally, these findings can be presented to the students which can act as a motivational tool for their encouragement in keeping high attendance level.

A provision of an attendance monitoring system in each institute can track students with poor attendance. Such students can be taken care of earliest in terms of motivation or finding other reasons for their absenteeism.

\section{ACKNOWLEDGEMENT}

We extend our sincere gratitude to the HOD of anatomy department for granting permission to access the data for conducting present study

\section{REFERENCES}

1. Chilwant, K.S., Hundekari, J.C.(2013). Effect of class attendance on performance in 2nd year medical students. IOSR J Res Method Educ, 3(3):31-3.

2. Daud, S., Javaid, F.(2006). Effect of class attendance of medical students' test performance. Pak J Med Health Sci, 6(2):295-7.

3. Hamdi, A. (2006). Effect of lecture absenteeism on pharmacology course performance in medical students. J Int Assoc Med Sci Educ, 16(1):27-30. 
4. Marcus, Crede, Sylvia G.R., Urszula, M., Keiszczynca. (2010). Class attendance in college: A meta analytic review of the relationship of class attendance with grades and student characteristics. Rev Educl Res, 80(2):272-295.

5. Mohanan, L.K., Harichandran, D.T., Vijayan, S.M. (2017). Association of class attendance and academic performance of MBBS students in pharmacology - A retrospective cohort study. Natl J Physiol Pharm Pharmacol ,7(10):1056-1060.

6. Sangeeta. M., Varalakshmi, K.L. (2019). Association between class attendance and internal assessment marks in anatomy. Indian J Clin Anat Physiol, 6(1):38-40.

7. Varul, M., Vegad, A., Shah, C., Mehta, H., Kacha, Y. (2016). Attendance, attitudes and academic performance: A study on first year MBBS students attending physiology classes. Int $\mathbf{J}$ Med Sci Educ, 3(1):31-7.

8. Victoria, A., Richard, E. (2016). Does class attendance predict academic performance in first year psychology tutorials? Int. Journal of psychological studies, $8(1)$; 28-32. 